\title{
SUNNAH, SAINS DAN PERADABAN MANUSIA; MENELAAH KEMBALI PEMIKIRAN YUSUF AL QARDHAWI
}

\author{
Ahmad Putra' dan Prasetio Rumondor² \\ 1,2UIN Sunan Kalijaga Yogyakarta
}

\begin{abstract}
Di era ini, muncul beranekaragam pemikiran yang berujung pada permasalahan dalam bidang sains (ilmu pengetahuan). Maka kajian tentang pemikiran Yusuf al Qardhawi menarik dikupas kembali untuk memberikan kerangka berpikir yang bersandar pada as Sunnah sebagai dasar hukum Islam yang kedua. Studi pustaka ini bertujuan untuk menganalisis pemikiran Yusuf al Qardhawi tentang Sunnah sebagai sumber ilmu pengetahuan dan peradaban. Selanjutnya artikel ini diharapkan dapat merefleksikan pemikiran tersebut dalam kehidupan intelektual. Penulis berkesimpulan bahwa, bagi Yusuf al Qardhawi, Sunnah merupakan tafsir praktis terhadap al-Qur'an dan aplikasi ideal dalam peradaban Islam. Sunnah juga memberikan keterkaitan yang kuat pada perkembangan ilmu pengetahuan manusia. Penulis berargumen, dengan menjadikan Sunnah sebagai sumber pengetahuan dan peradaban, sebenarnya al Qardhawi menekankan pada penggunaan akal yang merujuk kepada Sunnah sebagai sumber kontekstual.

Kata Kunci: Sunnah; Ilmu Pengetahuan; Peradaban; Yusuf al Qardhawi
\end{abstract}

ABSTRAK

\section{ABSTRACT}

In this era, a variety of thoughts emerged that led to problems in the field of science. So the study of Yusuf al-Qardhawi's thoughts is interesting to review again to provide a framework which relies on as Sunnah as the basis of the second Islamic law. This literature study aims to analyze Yusuf al Qardhawi's thoughts about the Sunnah as a source of science and human civilization. Furthermore this article is expected to reflect these thoughts in intellectual life. The author concludes that, for Yusuf al-Qardhawi, the Sunnah is a practical interpretation of the Qur'an and its ideal application in Islam. The Sunnah also provides a strong connection to the development of human civilization. The author argues, by making the Sunnah a source of knowledge and civilization, al-Qardhawi actually emphasizes the use of reason that refers to the Sunnah as a contextual source.

Keywords: Sunnah; Science; Civilization; Yusuf al Qardhawi

\section{A. Pendahuluan}

Al-Qur'an merupakan sumber yang paling utama dalam ajaran Islam, sedangkan sumber yang kedua setelahnya ialah hadis Nabi. Sehingganya, hadis Nabi menjadi sumber yang kedua setelah Al-Qur'an. Hadis berasal dari perkataan, perbuatan, tutur kata Nabi yang bagaimanapun tetap disandarkan kepada Al-Qur'an. Dengan kata lain, al-Qur'an juga menuntun keberadaan hadis hingga sampai zaman mengalami perubahan kepada kemajuan seperti saat ini. Keberadaan sunnah yang diposisikan menjadi sumber ajaran yang kedua setelah Al-Qur'an memberikan penguatan akan adanya sebuah aturan dan pedoman bagi manusia. Sehingga tidak ada alasan atau 
kekeliruan yang perlu dikritik ataupun yang perlu diperselisihkan dalam hidup beragama. ${ }^{1}$ Semua ini dikarenakan umat Islam sama-sama meyakini ada Allah SWT yang menjadi pilar penting bagi semua manusia serta yakin bahwa Rasulullah adalah manusia pilihan yang menjadi contoh bagi umat yang telah Allah pilih.

Yusuf Qadhawi merupakan sosok intelektual yang sekaligus menjadi ulama kontemporer yang cukup disegani dalam dunia ilmu pengetahuan Islam. Berkat pengetahuan yang ia miliki, menjadikan ia tokoh yang mampu menguraikan serta mengkaji sunnah sebagai ilmu pengetahuan dan peradaban. ${ }^{2}$ Ini mengambarkan bahwa pengetahuan yang ia miliki bukan hanya sekedar apa yang terlihat pada pendidikan yang dijalaninya, akan tetapi terbukti pada beberapa karya telah ia hadirkan. Dengan demikian, kajian Sunnah yang ia jelaskan tetap berpengaruh pada ilmu pengetahuan dan peradaban sampai zaman modern hari ini. ${ }^{3}$

Penelitian ini adalah penelitian kepustakaan (library research) yaitu penelitian yang dilaksanakan dengan mengunakan literatur (kepustakaan) baik berupa buku, catatan maupun laporan hasil penelitian dari peneliti terdahulu. Sumber data penelitian ini adalah sumber data primer dan sumber data sekunder. Adapun sumber data primernya buku karangan Yusuf Qardhawi yang berjudul Al-Sunnah Sebagai Sumber Pengetahuan Dan Peradaban. Sedangkan sumber data sekundernya adalah karya-karya lain yang membahas tentang Al-Sunnah Sebagai Sumber ilmu Pengetahuan.

\section{B. Sketsa Biografis Yusuf al Qardhawi}

Yusuf al Qardhawi lahir di desa Shafat Thurab, Mesir bagian Barat, pada tanggal 9 September 1926. Desa tersebut ialah tempat dimakamkannya salah seorang sahabat Rasulullah SAW yaitu Abdullah bin Harits r.a. ${ }^{4}$ Yusuf al Qardhawi berasal dari keluarga yang taat beragama. Ketika berusia 2 tahun, ayahnya meninggal dunia. Sebagai anak yatim ia hidup dan diasuh oleh pamannya, yaitu saudara ayahnya. la mendapat perhatian cukup besar dari pamannya sehingga ia menganggap pamannya itu sebagai orang tuanya sendiri. Seperti keluarganya, keluarga pamannya pun taat menjalankan agama Islam. Sehingga ia terdidik dan dibekali dengan berbagai ilmu pengetahuan agama dan syari'at Islam. ${ }^{5}$

\footnotetext{
${ }^{1}$ Baca, W.B. Hallaq, An introduction to Islamic Law (Cambridge: Cambridge University Press, 2009).

2 Siti Fahimah, "Hermeneutika Hadis: Tinjauan Pemikiran Yusuf Al-Qordhowi dalam Memahami Hadis”, Refleksi, Vol. 16, No. 1, (April 2017).

3 Hammam bin Abdurrahim Sa'id, al-Fikr al-Manhaji 'inda alMuhadditsin (Qatar : Ri'asat al-Mahakim alSyar'iyyat wa al-Syuun al-Diniyyat, 1998), 57.

4 Yusuf Al-Qardhawi, Fatawa Qardhawi, terj. H. Abdurrahman Ali Bauzir (Surabaya: Risalah Gusti, 1996), 399.

${ }^{5}$ Yusuf Al-Qardhawi, Pasang Surut Gerakan Islam, terj. Faruq Uqbah (Jakarta: Media Dakwah, 1987), 153. 
Berkat didikan agama, ia mulai menghapal Al-Qur'an ketika berumur 5 tahun, ia juga sekolah pada sekolah dasar bernaung di bawah lingkungan departemen pendidikan dan pengajaran Mesir untuk mempelajari ilmu umu, seperti berhitung, sejarah, kesehatan dan ilmu-ilmu lainnya. Berkat keseriusan dan semangat, ia berhasil menghapal Al-Qur'an 30 juz dalam usia 10 tahun. Bukan hanya sampai disana, kefasihan dan kebenaran tajwid serta kemerduan qiraatnya menyebabkan ia sering disuruh menjadi Imam Masjid.

Setelah menjalani pendidikan di sekolah, kecerdasannya mulai Nampak ketia ia berhasil menyelesaikan kuliahnya di Fakultas Ushuluddin al-Azhar dengan prediket terbaik yang diraihnya pada tahun 1952-1953. Kemudian ini melanjutkan pendidikannya kejurusan Bahasa Arab selama dua tahun. Tidak berbeda ketika dia lulus dari Fakultas Ushuluddin, di jurusan inipun dia lulus dengan rangking pertama di antara lima ratus mahasiswa. Dia memperoleh ijazah internasional dan sertifikat mengajar. ${ }^{6}$

Pendidikan dan prestasi Yusuf al Qardhawi sangat luar biasa dan ia memiliki berbagai pengetahuan terkait dengan keilmuan agama. Salah satu dari sekian banyak tokoh yang ia kagumi ialah Hasan al-Banna. Menurutnya, Hasan Al-Bana merupakan tokoh karismatik yang menggabungkan antara pemikiran keagamaan dan politik, antara unsur spiritual dan semangat jihad, idealism dan pergerakan, serta Al-Bana juga sebagai pendiri dan pemimpin besar Ikhwanul Muslimin di Mesir. Kecintaannya dengan Hasan al-bana menjadikan Yusuf termotivasi dan kagum dengan alur dakwah yang ia dapatkan.

Yusuf Al Qardhawi sebagai seorang ilmuan yang memiliki banyak kreativitas dan aktivitas. juga berperan aktif di lembaga pendidikan. Jabatan structural yang sudah lama dipegangnya adalah ketua Jurusan Studi Islam pada Fakultas Syari'ah Universitas Qatar. la juga pernah menjadi Dekan Fakultas Syari'ah Universitas Qatar. Sebelumnya ia adalah direktur lembaga agama tingkat sekolah lanjutan atas di Qatar.

Melihat kepada sejarah, Yusuf juga pernah menjadi aktivis gerakan al-Ikhwan al-Muslimun sejak duduk di sekolah lanjutan atas. la pernah menjadi anggota Departemen gerakan al-lkhwan al-Muslimin yang dipimpin oleh al-Bahiy al-Khuliy. Keterlibatannya sebagai aktivis Ikhwan al-Muslimin membuatnya aktif menggerakkan dan memimpin demonstrasi anti imperialism Barat dan Israel. la pernah dijebloskan

\footnotetext{
${ }^{6}$ Muhammad Al-Madjzub, 'Ulama Wa Mufakkirun 'Araftuhum (Beirut: Dar al-Nafais, 1977), 442-443.
} 
kedalam penjara selama 20 bulan dan pada tahun 1962 ia dipenjarakan selama 50 hari bersama Dr. Ahmad 'Assal.'

Setelah Hasan Al-Banna, Yusuf juga mengagumi sosok Abu al-Hasan al-Nadawy. Bagi Yusuf, ia merupakan seorang modernis yang integralistik, ia dapat diterima oleh semua aliran serta kalangan Islam di India dan dunia Islam, yang memungkinkannya berperan dalam menghilangkan berbagai penyebab pertikaian yang terjadi di India. Dengan demikian, Yusuf al Qardhawi banyak belajar dari buku-buku al-Nadawy yang juga ia jadikan sebagai sumber rujukannya. Al Qardhawi mengatakan hamper semua da'l kontemporer dan pemikir Islam mengambil manfaat dari bukunya dan juga berguru kepada Nadawy secara langsung, sampai Nadawy mendapat julukan Imam Islami, Qurani, Muhamadi dan 'Alami. ${ }^{8}$

Yusuf Qardhawi adalah seorang ulama yang tidak hanya menganut suatu mazhab tertentu. la mengatakan "saya tidak rela rasioku terikat dengan satu mazhab dalam seluruh persoalan, salah besar jika mengikuti hanya satu mazhab saja. la sependapat dengan ungkapan Ibnu Juz'ie tentang dasar muqallid yaitu tidak dapat dipercaya tentang apa yang diikutinya itu dan taqlif itu sendiri sudah menghilang rasion, itu diciptakan untuk berfikir dan menganalisa, bukan semata-mata untuk mengtaqlid. Aneh sekali bila seseorang diberi lilin tetapi ia berjalan dalam kegelapan. 9

Al Qardhawi mempunyai keluarga yang tenang yang Allah karuniakan sejak bulan Desember 1958. Istrinya seorang wanita yang shalihah dari keluarga Hasyimiyah Husainiyah. Istrinya sangat sabar dalam menghadapi semua tantangan dakwah, dimana sering kali suaminya banyak mengutamakan umat dari pada keluarganya sendiri. AlQaradhawi memiliki tujuh anak, empat putri dan tiga putra. Sebagai seorang ulama yang sangat terbuka, dia membebaskan anakanaknya untuk menuntut ilmu apa saja sesuai dengan minat dan bakat serta kecenderungan masing-masing. Al-Qaradhawi tidak membedakan pendidikan yang harus ditempuh anak-anak perempuan dan anak laki-lakinya. ${ }^{10}$

Putri sulungnya, Ilham keluar dengan nilai tertinggi di Universitas Qatar dan meraih gelar Doktor dalam bidang Fisika jurusan Nuklir dari Universitas London. Putri

\footnotetext{
7 Ibid., 450

8 Yusuf Al-Qardhawi, Hasan Al-Nadwi Dalam Kenangan Yusuf al-Qardhawi (Jakarta: Kafila Press, 2000 ), 2.

9 Yusuf Al-Qardhawi, Halal Dan Haram Dalam Islam, terj. H. Muammal Hamidy (Surabaya: PT Bina Ilmu, 1976), 5.

10 M. Abdul Ghoffar, Pemikiran Dr. Yusuf al-Qaradhawi Dalam Timbangan (Bogor: Pustaka Imam Asy-Syafi'i, 2003), 8. 
keduanya, Siham, alumnus Universitas Qatar dengan nilai tertinggi pada jurusan Kimia, dan memperoleh gelar Doktor dari satu Universitas di Inggris dalam bidang Biologi jurusan Organ Tubuh. Putri ketiganya, 'Ala, memperoleh nilai tertinggi dari Fakultas Biologi jurusan Hewan dan memperoleh gelar Master dari Universitas Texas di Amerika dalam bidang Rekayasa Genetik. Putri keempatnya, Asma', memperoleh gelar Master dari Universitas Khalif Bahrain dan sedang mengambil program Doktor di Universitas Nottingham Inggris bersama suaminya. Sedangkan anak laki-lakinya yang pertama, Muhammad, alumnus Fakultas Teknik jurusan Mesin dari Universitas Qatar dan mengambil program Doktor di Amerika. Anak laki-lakinya yang kedua, Abdur Rahman, menempuh jalur yang berbeda dengan kakak-kakaknya, dia masuk pada sebuah Akademi Keagamaan di Qatar. Anak laki-lakinya yang bungsu, Usamah, alumni Fakultas Teknik jurusan Elektro. ${ }^{11}$

Yusuf Qardhawi dikenal sebagai ulama dan pemikir Islam yang unik sekaligis istimewa, keunikan dan keistimewaanya itu tak lain dan tak bukan ia memiliki cara atau metodologi khas dalam menyampaikan risalah Islam, lantaran metodologinya itulah dia mudah diterima di kalangan dunia barat sebagai seorang pemikir yang selalu menampilkan Islam secara ramah, santun, dan moderat, kapasitasnya itulah yang membuat Qardhawi kerap kali menghadiri pertemuan internasional para pemuka agama di Eropa maupun di Amerika sebagai wakil dari kelompok Islam.

Dalam lentera pemikiran dan dakwah Islam, kiprah Yusuf Qardhowi menempati posisi vital dalam pergerakan Islam kontemporer, waktu yang dihabiskannya untuk berkhidmat kepada Islam, bercearamah, menyampaikan masalah masalah aktual dan kelslaman di berbagai tempat dan negara menjadikan pengaruh sosok sederhana yang pernah dipenjara oleh pemerintah mesir ini sangat besar di berbagai belahan dunia, khususnya dalam pergerakan Islam kontemporer melalui karya karyanya yang mengilhami kebangkitan Islam moderen. Sekitar 125 buku yang telah beliau tulis dalam berbagai demensi kelslaman, sedikitnya ada 13 aspek kategori dalam karya karya Yusuf Al Qardhawi, seperti masalah masalah: fiqh dan ushul fiqh, ekonomi Islam, ulum Al Quran dan As sunnah, akidah dan filsafat, fiqh prilaku, Dakwah dan Tarbiyah, gerakan dan kebangkitan Islam, penyatuan pemikiran Islam, pengetahuan Islam umum, serial tokoh-tokoh Islam, sastra dan lainnya. Sebagian dari karyanya itu telah diterjemahkan

11 Ishom Talimah, Al-Qardhawi Wa Fiqiha, terj. Samson Rahman “Manhaj Fiqih Yusuf Qardhawi” (Jakarta: Pustaka Al-Kautsar, 2001), 20. 
ke berbagai bahasa termasuk bahasa Indonesia, tercatat, sedikitnya 55 judul buku Qardhawi yang telah diterjemahkan ke dalam bahasa Indonesia. ${ }^{12}$

Berikut sejumlah buku karya Qardhawi dalam bidang Fiqh dan Usul Fiqh. Sebagai seorang ahli fiqh, Qardhawi telah menulis sedikitnya 14 buah buku, baik Fiqh maupun Ushul Fiqh. Antara lain Al-Halal wa al Haram fi al-Islam (Halal dan Haram dalam Islam), Al-Ijtihad fi al-Shari'at allslamiah (Ijtihad dalam syariat Islam), Fiqh alSiyam (Hukum Tentang Puasa), Fiqh alTaharah (Hukum tentang Bersuci), Fiqh alGhina' wa al-Musiqa (Hukum Tentang Nyayian dan Musik). Dalam bidang ekonomi Islam, buku karya Qardhawi antara lain, Fiqh Zakat, Bay'u al-Murabahah li al-Amri bi al-Shira; (Sistem jual beli al-Murabah), Fawa'id alBunuk Hiya al-Riba al-Haram, (Manfaat Diharamkannya Bunga Bank), Dawr al-Qiyam wa al-Akhlaq fi al-lqtisad alIslami (Peranan nilai dan akhlak dalam ekonomi Islam), serta Dur al-Zakat fi alaj alMusykilat al-Iqtisadiyyah (Peranan zakat dalam Mengatasi Masalah ekonomi). Pengetahuan tentang al-Quran dan al Sunnah. Qardhawi menulis sejumlah buku dan kajian mendalam terhadap metodologi mempelajari Alquran, cara berinterakhsi dan pemahaman terhadap Alquran maupun Sunnah. Buku-bukunya antara lain Al-Aql wa alllm fi al-Quran (Akal dan Ilmu dalam al-Quran), Al Sabru fi al-Quran (Sabar dalam alQuran), Tafsir Surah al-Ra'd dan Kayfa Nata'amal ma'a al Sunnah al-Nabawiyyah (Bagaimana berinteraksi dengan sunnah). Dalam bidang Akidah Islam, Qardhawi menulis sekitar empat buku, antara lain Wujud Allah (Adanya Allah), Haqiqat alTawhid (Hakikat Tauhid), Iman bi Qadr (Keimanan kepada Qadar).

\section{Sunnah sebagai Sumber Ilmu Pengetahuan}

Al-Qaradhawi memandang bahwa sunnah merupakan tafsir praktis terhadap alQur'an dan aplikasi ideal dalam Islam. Posisi Nabi Muhammad dalam hal ini adalah sebagai penafsir al-Qur'an sekaligus representasi dari Islam itu sendiri. Artinya, setiap bentuk aktiftas maupun perilaku beliau merupakan representasi dari ajaran Islam. Hal ini diperkuat dengan adanya sebuah riwayat dari sayyidah 'Aisyah yang berbunyi: "Akhlak Nabi adalah al-Qur'an”. Dengan demikian, menurut al-Qaradhawi, ketika seorang hendak mengenal dan memperdalam pengetahuan tentang ajaran Islam, maka ia harus menempuhnya melalui pengetahuan tentang as-Sunnah. ${ }^{13}$ Sunnah merupakan sumber acuan kedua bagi Islam setelah al-Qur'an. Di dalamnya terdapat penjelasan

\footnotetext{
12 Risna Mosiba, 2017, "SUNNAH SEBAGAI SUMBER IPTEK DAN PERADABAN (Studi atas Pemikiran Yusuf AlQardhawi)", Inspiratif Pendidikan, vol. 6, no. 2 (Juli, 2017), 369.

13 Yusuf Al-Qardhawi, Kayfa Nata'amal Ma'as Sunnah an Nabawiyah (Beirut: Darul Wafa, 1993), 24. 
teoritis dan praktek terapan bagi al-Qur'an, oleh karenanya, menurut al Qaradhawi umat Islam harus mengamalkan isi dari sunnah yang berupa ajaran-ajaran dan pengarahan-pengarahannya. ${ }^{14}$

la menyatakan bahwa sunnah di samping sebagai sumber ajaran yang bersifat dogmatisteologis, sunnah juga berperan sebagai sumber ilmu pengetahuan agama maupun ilmu sains. Lebih dari itu, sunnah juga menjadi sumber peradaban. Bersama al-Qur'an, sunnah memuat ajaran tentang apa yang disebut dengan al-Wa'yu alHadlari (kesadaran peradaban). Dalam ungkapan yang lebih dekat kepada Islam, hal ini juga disebut sebagai al-Fiqh al-Hadlari (Fiqih peradaban), yaitu fqih yang menghantarkan manusia dari pemahaman dangkal dan primitive menuju pemahaman yang luas dan mendalam mengeni akal dan kehidupan. ${ }^{15}$

1. Ilmu Pengetahuan: Antara Indra, Akal dan Wahyu

Indra dan rasio merupakan sarana yang amat penting serta nikmat yang amat besar yang dianugerahkan Allah kepada manusia untuk mengetahui dirinya sendiri dan alam di sekitarnya. Dengan itu, manusia dapat menangkap ketentuan dan rahasia-rahasia yang tersimpan di alam raya ini, yang dapat menjadi bukti yang paling valid atas keberadaan Allah SWT, yang telah menciptakaan seluruh semesta alam ini dengan sebaik-baiknya. Allah berfirman:

"Dan Allah mengeluarkan kamu dari perut ibumu dalam keadaan tidak mengetahui sesuatupun, dan Dia memberi kamu pendengaran, penglihatan, dan hati, agar kamu bersyukur" (QS. An-Nahl: 78). ${ }^{16}$

Keutamaan ilmu pengetahuan yang dimiliki oleh Adam, nenek moyang semua manusia adalah salah satu kelebihan manusia yang paling besar atas semua malaikat, dan membuatnya layak untuk memegang tampuk kekhalifahan di muka bumi. Allah telah mengajarkannya nama-nama yang tidak diketahui oleh para malaikat. Ini adalah satu bentuk hikmah yang besar yang ingin Allah tunjukkan. Sesuai dengan firman-Nya:

"Sesungguhnya Aku mengetahui apa yang tidak kamu ketahui". ${ }^{17}$

Umat Islam di samping mempercayai dua sumber ilmu pengetahuan, juga mempercayai sumber yang lebih tinggi dari itu, yaitu wahyu ilahi. Allah telah menganugerahkan kepada manusia jumlah perangkat kognitif sebagian perangkat

${ }^{14}$ Yusuf Al-Qardhawi, Pengantar Kajian Islam (Jakarta: Pustaka al-Kautsar, 2000), 380.

${ }^{15}$ Yusuf Al-Qardhawi, As-Sunnah Sebagai Sumber Iptek dan Peradaban (Jakarta: Pustaka Al-Kautsar, 1999$), 248$.

16 Departemen Agama RI, Al-Qur'an dan Terjemahnya, Revisi Terjemah Oleh Lajnah Pentashih Mushaf Al-

Qur'an Departemen Agama RI (Surabaya: CV Fajar Mulya, 2009), 275.

17 QS. Al-Baqarah: 30. 
itu ada yang lebih baik dari yang lain yang akan menuntunnya untuk mengetahui dirinya sendiri, alam di sekitarnya, serta mengetahui asal, kembali, dan misi yang diembannya. Allah SWT mnganugerahkan beberapa indra, yang paling utama adalah indra pendengaran dan penglihatan, agar dengannya manusia dapat berinteraksi dengan semesta tempat ia hidup, apa yang ada di dalamnya, serta makhlukmakhluk yang hidup di sana. Kemudian manusia menggunakan semua itu untuk mencapai tujuan yang ditetapkan oleh Allah SWT dalam penciptaan manusia. ${ }^{18}$

Akan tetapi, indra manusia mempunyai keterbatasan tersendiri, dan ia juga dapat keliru. Ini terjadi pada semua indra, hingga indra yang paling kuat sekalipun, yaitu mata. Misalnya, mata melihat suatu bayangan sebagai sesuatu yang diam, padahal ia bergerak. Melihat fatamorgana dan menyangkanya sebagai air, namun ketika didekati ternyata bukan. Demikian juga ketika ia melihat sesuatu yan sebenarnya besar tapi tampak kecil karena letaknya yang jauh, seperti bintang di langit. Oleh karena itu, Allah SWT menganugerahkan perangkat yang lebih tinggi, taitu akal, yang dapat meluruskan kesalahan indra. Dengan rasio itu manusia dapat memahami segala yang dapat dipahaminya, seperti perhitungan matematis, pokokpokok pemikiran, dan segala hal selain bentuk-bentuk parsial yang dapat dindra.

Akal dapat pula membedakan manusia dari semua hewan. Dengan akal, manusia dapat mengenal dirinya, dunianya, Rabbnya dan ia pula seperti yang dikatakan oleh para ahli ushul fiqh, pokok pertimbangan dibebankannya hukum kepada manusia. Akal juga mampu membedakan mana yang hakiki dan mana yang ilusi, serta mana yang yakin dengan praduga. Namun akal juga dapat dipengaruhi oleh ketergesa-gesaan, kesombongan, hawa nafsu, lingkungan sekitarnya, warisan keagamaan dan peradaban yang berkembang, baik pengaruh itu positif atau negatif. ${ }^{19}$

Akal juga menyadari bahwa medan yang ia masuki terbatas. la hanya dapat memahami sedikit dari sisi-sisi alam ini bahkan ia tidak mengetahui dirinya sendiri, bagaimana bekerja dan bagaimana menangkap ilmu pengetahuan dan ia hanya mengetahui aspek luar dari sesuatu. Oleh karena itu, Imam Muhammad Abduh mengatakan bahwa akal itu membutuhkan teman yang dapat menuntunnya melewasti persimpangan jalan ini, sehingga ia tidak tergelincir. Pada wilayah yang terlarang untuk dimasuki akal, maka penolong ini akan memberitahukannya apa yang tidak ia ketahui dan menyelamatkannya dari kebingungan, serta memberikan

\footnotetext{
${ }^{18}$ Jalaluddin Rakhmat, Islam Alternatif (Bandung: Mizan, 1999).

${ }^{19}$ Harun Nasution, Kedudukan akal dalam Islam (Jakarta: Yayasan Idayu, 1982). 
ketenangan dan pembenaran atas apa yang telah diketahui oleh akal. Sehingga baginya, ia menjadi cahaya di atas cahaya. Teman yang membantu ini adalah wahyu ilahi, yang diberikan Allah SWT melalui rasul-rasul-Nya, yang terangkum dalam risalah penutup: Al-Qur'an al-Karim, yang merupakan akhir kalimat-kalimat Allah SWT bagi petunjuk manusia, serta Sunnah Nabi Muhammad yang menjadi penjelas bagi Al-Qur'an ini.

Akal adalah perkara pokok di dalam agama. Ayat-ayat yang membahas akal baik dalam bentuk akal itu sendiri atau bentuk lain mencapai hamper 1000 ayat. Melainkn akal berbeda-beda pada masing-masing orang, karenanya kita menyifati akal dengan kata sehat, sebab ada akal pragmatis yang erat kaitannya dengan hawa nafsu dan kepentingan. Seseorang yang berakal menjalani kehidupan yang tenang, kehidupan penuh keselamatan, kehidupan penuh kebahagiaan, sebab dia mengambil apa yang menjadihaknya dan meninggalkan apa yang bukan haknya. Dia bergerak dengan eksistensinya dirinya dan membangun hubungan dengan prinsip yang jelas, sehingga orang-orang mencintainya. Dia mengupayakan harta yang halal, dia membangun keluarga dan mendidik anak-anak, dia menggunakan akalnya untuk akhirat, sehingga ia berhasil mendapatkannya. ${ }^{20}$

2. Sunnah sebagai Sumber Pengetahuan Agama

Secara etimologis, kata "Sunnah" berarti arah, peraturan, mode atau cara tentang tindakan atau sikap hidup. ${ }^{21}$ la juga dapat diartikan sebagai jalan, apakah jalan tersebut baik ataupun bersifat buruk. ${ }^{22}$ M. Ajjal al-Khatib (dalam Abdul Haris) mengatakan bahwa secara terminologi, sunnah berarti segala perkataan, perbuatan, taqrir, sifat kemanusiaan atau sifat moralistik, atau perjalanan hidup (sirah), yang diwarisi dari Nabi SAW baik ketika beliau dalam fase sebelum diutus sebagai rasul maupun setelah diutus sebagai rasul. ${ }^{23}$

Pendapat lain mengatakan bahwa sunnah menurut jumhur ulama sama dengan penegertian hadis, yaitu segala yang dinukil dari Nabi Muhammad, baik berupa perkataan, perbuatan, maupun takrir dan sifat-sifat beliau (berupa perilaku, pengajaran dan perjalanan hidup), baik sebelum maupun setelah diutus menjadi rasul. Akan tetapi, sebagian ulama ada yang tidak memasukkan takrir (pengakuan

\footnotetext{
${ }^{20}$ Ratib An-Nabulsi, 7 Pilar Kehidupan (Jakarta: Gema Insani Press, 2010), 43.

${ }^{21}$ M. M. Azami, Studies in Hadith Methodology and Literature (Indianapolis: American Trust Publication, 1997), 3.

${ }_{22}$ M. Ajjaj Al-Khatib, Al-Sunnah Qabl al-Tadwin (Dar al-Fikr, 1981), 14.

${ }^{23}$ Ibid., 16
} 
Nabi Muhammad), ke dalam pengertian sunnah. ${ }^{24}$ Untuk memahami sunnah dengan pemahaman yang benar, jauh dari penyimpangan, pemalsuan, dan penafsiran yang buruk, maka haruslah kita memahaminya sesuai dengan petunjuk Al-Qur'an, yaitu dalam kerangka bimbingan ilahi yang pasti benarnya dan tak diragukan keadilannya. ${ }^{25}$

Sunnah adalah sumber dakwah dan tuntunan hidup. la juga menjadi sumber pengetahuan bagi umat Islam (pengetahuan agama, kemanusiaan, dan social) yang dibutuhkan oleh manusia, sebagai petunjuk jalan bagi mereka, atau meluruskan langkah mereka. Atau juga untuk menyempurnakan ilmu yang telah mereka miliki. Dalam Sunnah dan Al-Qur'an terdapat banyak berita yang berkaitan dengan alam gaib, alam yang tidak terlihat oleh kita dan tidak dapat ditangkap oleh indra kita, yang hanya dapat diketahui melalui wahyu ilahi. Dalam sunnah juga ada berita masa lalu seperti awal penciptaan manusia, tentang rasul-rasul dan nabi-nabi. Dalam Sunnah juga terdapat berita-berita tentang kejadian-kejadian yang berkaitan dengan masa yang akan datang, yang akan terjadi sebelum hari kiamat, yang akan terjadi setelah kiamat seperti pembangkitan kembali dan pengumpulan manusia, perhitungan serta surga dan neraka. Semua itu disebutkan oleh Al-Qur'an dan dijelaskan oleh Sunnah. Dengan demikian, sunnah harus ditegakkan dan dijalani dengan sebaik-baiknya. Karena seseorang yang menegakkan Sunnah Nabi, maka ia akan mendapatkan pahala seratus kali orang yang mati syahid. ${ }^{26}$

3. Seputar Alam Gaib

Alam gaib berada di sekitar kita, hanya saja indra dan akal manusia memiliki keterbatasan dalam mengetahui perihal itu. Diantara alam gaib itu, malaikat, jin, arsy, kursi, lauh, dan sebagainya. Yang disebutkan dalam Al-Qur'an, biasanya secara general, dan pada suatu kesempatan secara terperinci dan Sunnah, biasanya berbicara secara lebih rinci lagi tentang itu. Kaum muslimin sepakat bahwa Sunnah adalah sumber pengetahuan tentang hal-hal yang berkaitan dengan perkara-perkara yang gaib. Mereka telah menemukan dari dalil-dalil yang pasti bahwa Muhammad SAW adalah utusan Allah SWT dan mendapatkan wahyu. Beliau tidak berbicara dengan dorongan hawa nafsu, hanya berkata yang benar, tidak berkata tentang ilmu Allah apa yang beliau tidak ketahui, dan beliau tidak mengetahui yang gaib kecuali sekedar apa yang yang dibukakan bagi beliau oleh Allah SWT.

\footnotetext{
${ }^{24}$ M. Alfatih Suryadilaga, Ulumul Hadits (Yogyakarta: Teras, 2010), 22.

25 Yusuf Al-Qardhawi, Bagaimana Memahami Hadits Nabi SAW (Bandung: Karisma, 1993), 92.

26 Jalaludin As-Suyuthy, Argumentasi As-Sunnah (Surabaya: Risalah Gusti, 1996), 21. 
Setelah manusia itu mengakhiri hidupnya di alam dunia yakni ia telah mati, maka untuk selanjutnya ia dikuburkan dan selanjutnya mengalami perpindahan alam lagi yaitu menempuh kehidupan di alam kubur (barzakh). Adapun sifat dan keadaan alam yang ketiga atau alam barzakh ini adalah lebih luas lagi dari keadaan alam dunia sekarang ini. sebagai perumpamaan dapatlah dikatakan bahwa perbandingan antara alam barzakh dengan alam dunia sekarang ini adalah sebagaimana perbandingan antara alam dunia sekarang dengan alam sewaktu masih dalam kandungan ibu. ${ }^{27}$

Adapun kehidupan di alam barzakh ini sifatnya juga hanya sementara waktu, yaitu hingga datangnya hari kiamat. Sebab setelah datangnya hari kiamat nanti akan ada kehidupan lagi yaitu kehidupan tahap yang keempat (terakhir), yaitu kehidupan di alam akhirat.

4. Sunnah sebagai Metode Penyeimbang

Di samping sebagai metode yang mencakup segala aspek kehidupan manusia, Sunnah juga merupakan satu bentuk jalan yang berusaha mengatur umatnya agar senantiasa hidup secara proporsional dan berimbang. Sunnah memberikan petunjuk kepada umat Islam agar selalu bersikap seimbang dalam memperlakukan jasad dan ruh, akal dan hati, dunia dan akhirat, kebebasan dan tanggung jawab dsb. la adalah manhaj tengah, jalan atau metode moderat bagi seluruh umat. Semangat yang terkandung dalam as-Sunnah adalah semangat moderat. Bersikap ekstrim dan berlebih-lebihan dalam menyikapi maupun melaksanakan sesuatu adalah tindakan yang tidak mencerminkan Islam.

Di antara karakteristik sunnah adalah sifatnya yang mudah dan tidak mempersulit. Nilai-nilai ajaran yang terkandung dalam asSunnah adalah nilai-nilai yang masih dalam taraf kemampuan manusia. Rasulullah diutus oleh Allah sebagai rahmat bagi alam dan salah satu representasi dari rahmat tersebut adalah dengan memberikan kemudahan-kemudahan kepada umat Islam dalam menjalankan ajaran agamanya. ${ }^{28}$

5. Titik Silang Pendapat

Terkait dengan perbedaan pendapat, terlihat bahwa titik perselisihan antara dua kelompok atau lebih belum diidentifikasi secara tepat. Seandainya titik titik permasalahan itu dilihat kembali secara baik, niscaya kelompok pendapat tersebut akan menemukan kesamaan pendapat. Kecuali orang yang bersikap sombong dan

27 Zainal Abidin, Alam Kubur Dan Seluk-Beluknya (Jakarta: PT Rineka Cipta, 1993), 12.

28 Yusuf Al-Qardhawi, Kayfa Nata'amal Ma'as Sunnah an Nabawiyah, 27. 
tidak jujur, terutama jika kita telah men-tarjih keharusan adanya sumber yang meyakinkan dalam membangun konsep akidah, sedangkan hadis ahad tanpa disertai petunjuk/qarinah tidak memberikan pengertian yang meyakinkan. ${ }^{29}$

Ada dua faktor yang kemudian turut menjadi bahan perselisihan, yaitu: Pertama, jika yang dimaksud dengan akidah adalah yang dihukumkan kafir jika orang yang mengingkarinya, maka orang yang mengingkari akidah yang telah ditetapkan oleh hadis shahih wajib dihukumkan kafir dan keluar dari agama Islam, seperti dilakukan oleh sebagian pemuda yang bersemangat dari madrasah atau kelompok hadis, dan barangkali juga didukung oleh sebagian ulama besar. Ini merupakan sebuah kekeliruan, karena kaum Ahlus-sunnah dengan seluruh bagiannya, yaitu Asy'ariah, maturidiah, Hambalia, kaum mutakallimin, pengikut atsar, fuqaha, dan kaum sufi, tidak mengkafir-kafirkan kelompok-kelompok itu dari Islam. Mereka hanya mengatakan bahwa kelompok-kelompok itu adalah pembuat bid'ah, tidak lebih. Meskipun kelompok-kelompok itu telah mengingkari beberapa hadis yang amat jelas, bahkan sebagian hadis itu ada yang mencapai derajat mutawatir. ${ }^{30}$

Kedua, jika masuk dalam perselisihan itu tentang hadis-hadis yang berkaitan dengan sifat-sifat Allah SWT. Seperti hadis tentang turunnya Allah SWT ke langit dunia pada sepertiga malam yang terakhir, tentang betis, telapak kaki, dua jari, jari tanan, dan sebagainya, yang telah menjadi perselisihan antara kaum salaf atau antara kaum yang menerima apa adanya dengan kaum yang berusaha melakukan ta'wil. ${ }^{31}$

\section{Sunnah sebagai Sumber Peradaban}

Sunnah nabawiyah adalah sumber kedua setelah Al-Qur'anul karim untuk penentuan hukum, dan dia juga sumber kedua untuk ilmu pengetahuan setelah AlQur'an. Selain itu, Sunnah juga merupakan sumber kedua bagi peradaban setelah kitab Allah. Al-Qur'an selalu meletakkan dasar-dasar dan prinsip-prinsip, sedangkan Sunnah memberikan penjelasan dan perincian pandangan. Sebagaimana dia juga memberikan teladan dan praktik pembuktian. Ada tiga perkara penting yang berkaitan dengan peradaban, yaitu fiqih peradaban, perilaku peradaban dan pembangunan peradaban.

\footnotetext{
${ }^{29}$ Yusuf al Qordhawi, al-ljtihad al-Mu'asir (Kairo: Dar al-Tauzi' wa an-Nashr allslamiyah,t.t), 4.

$30 \mathrm{lbid}$

31 Yusuf al Qardhawi, Bagaimana Memahami Hadits Nabi ,. Terj. M. Bagir (Jakarta: tp, 1993), 17. 
Dalam bahasa Arab, kata peradaban adalah lawan kata dari "Badui" atau "liar". Perkotaan berlawan kata "padang sahara”. Sedangkan "menetap” adalah kebalikan dari "nomaden". Adapun orang-orang yang hidupnya menetap adalah penghuni kota, desa dan pantai. Sedangkan orang-orang Badui adalah mereka yang tinggal di kemahkemah di padang pasir. Orang-orang Badui terkenal dengan perangainya yang kasar, kejam, keras, tampak lugu, dan buta huruf. Dikarenakan hal ini, Allah tidak mengutus seorang rasul pun dari suku Badui. Akan tetapi, semua rasul yang diutus oleh Allah semuanya berasal dari desa dan kota. Allah berkata kepada rasul-Nya:

"Kami tidak mengutus sebelum kamu, melainkan orang laki-laki yang Kami beri wahyu kepada mereka di antara penduduk negeri...".

Orang-orang Badui disebut juga orang yang kasar. Di dalam hadis dikatakan, "barangsiapa yang hidup di dusun padang pasir (Badui), maka dia akan bertemperamen kasar". Mereka menyebutkan bahwa tinggal di dusun padang pasir bersama orang Badui itu makruh, kecuali jika sedang terjadi fitnah (kerusakan moral atau perang saudara).

Islam datang untuk mengeluarkan manusia dari kegelapan menuju cahaya terang. Dari kegelapan dengan segala macam bentuk dan tingkatannya, menuju cahaya dengan berbagai macam bentuk dan tingkatannya. Salah satunya yaitu mengeluarkan mereka dari kegelapan kehidupan Badui dan kehidupan yang buas menuju kehidupan yang penuh cahaya peradaban dan kemajuan. Di dalam Al-Qur'an dikatakan,

"Orang-orang Arab Badui itu jauh lebih banyak kekafiran dan kemunafikannya, sehingga sangat wajar jika mereka tidak mengetahui hukumhukum yang diturunkan oleh Allah kepada rasul-Nya dan Allah itu Maha Mengetahui dan Maha Bijaksana". ${ }^{33}$

Akan tetapi, apa yang ditegaskan oleh ayat pertama itulah yang mewakili orang-orang Badui secara keseluruhan. Belum lagi diperkuat oleh sabda Rasul SAW.,

"Barangsiapa yang hidup di padang pasir (Badui), maka ia akan berperangai kasar”.

Lihatlah peristiwa tentang seorang Badui yang tidak merasa bersalah sewaktu buang air kecil di dalam masjid, padahal Rasulullah dan para sahabat sedang dudukduduk di situ. Kontan saja para sahabat memarahinya dan hampir membunuhnya. Akan tetapi, Nabi SAW memahami keadaan psikologisnya dan sifat kebaduiannya. Beliau berkata kepada para sahabatnya, "jangan kalian berhentikan dia (jangan memotong

32 QS. Yusuf: 109.

33 QS. At-Taubah: 97. 
kencingnya), tetapi siramkanlah seember air di atasnya. Karena aku ini diutus untuk memberikan kemudahan dan bukan untuk memberikan kesulitan". ${ }^{34}$

Yusuf Qardhawi menekankan bahwa Islam sejak pertama kali datang telah membawa misi peradaban yang tidak diragukan lagi. Tujuannya meningkatkan mutu kehidupan manusia dan mengeluarkannya dari kekolotan menuju kehidupan yang maju. Peradaban yang ingin dibangun oleh Islam bukanlah peradaban yang dimiliki oleh umat lain yang lebih banyak menekankan sisi materi dalam kehidupan, sisi tubuh dan naluri dalam diri manusia, dan kelezatan-kelezatan yang selera di dunia. Sehingga mereka menjadikan dunia sebagai tujuan utama dan terminal akhir dari ilmu yang dimilikinya. Tidak ada tempat tersisa untuk menyebut nama Allah dalam falsafah mereka. Tidak pula tersedia ruangan untuk akhirat dalam anatomi pemikiran dan pengajaran mereka.

Ini berbeda sekali dengan peradaban Islam. Dalam Islam, manusia benar-benar telah sampai kepada Allah, bumi pun telah terikat dengan langit, dunia dijadikan sebagai jembatan menuju akhirat, materi dipadu dengan spiritual, akal diseimbangkan dengan hati, dan ilmu disatukan dengan iman. Islam betul-betul gigih ingin meninggihkan kemajuan fisik. Dulu peradaban Islam benar-benar merupakan peradaban material-spritual. Peradaban ideal yang pernah terjadi, peradaban yang tidak pernah melupakan Tuhannya, dengan tetap memperhatikan sisi kemanusiaanya manusia. Peradaban yang penuh etika dan norma. Juga merupakan peradaban yang dibangun di atas dasar kerjasama yang baik antara individu dan jamaah. Dia adalah peradaban yang seimbang dan ideal, yang dibangun oleh umat yang terbaik.

\section{E. Kontekstualisasi Sunnah bagi Sains dan Peradaban Manusia}

Dengan menyimak tiga tema pokok dalam karya Yusuf al Qardhawi yang telah disebutkan, ditemukan beberapa gagasan penting beliau tentang eksistensi sunnah sebagai sumber Iptek dan Peradaban, sebagai berikut:

1. Universalisme Sunnah tentang Sains dan Peradaban

Secara tegas Alquran menyatakan bahwa hadis adalah sumber tasyri' di samping Alquran. ${ }^{35}$ Berkenaan dengan ini, Yusuf al Qardhawi menyatakan bahwa sebagian golongan telah menyalahgunakan tafsiran hadis-hadis itu sendiri. Misalnya saja, hadis masyhur yang matannya berbunyi: kalian lebih mengetahui urusan dunia

\footnotetext{
34 HR. Bukhari dalam al-Wudhu', Abu Daud (380), Tirmizi (148), dan Nasa'l (1/48, 99), semuanya dari Abu Hurairah.

${ }^{35}$ M. Syuhudi Ismail, Kaidah Kesahahihan Sanad Hadis (Jakarta: Bulan Bintang, 1990), 20.

El Banat Vol. 10 No. $1(2020)$
}

14 
kalian. ${ }^{36}$ Dengan memahami hadis ini, ada sebagian orang yang ingin menghapus sistim politik dalam Islam. Begitu, juga ada yang ingin menghapuskan seluruh system ekonomi dalam Islam. Mereka berusaha mengingkari sebagian syariah Islam dalam masalah muamalat, dan urusan sosial, karena dikategorikannya sebagai urusan dunia belaka. Berkenaan dengan hal tersebut, Yusuf al Qardhawi lalu menegaskan bahwa hadis tersebut secara eksplisit maknanya tidak bertentangan dengan nash dan tidak menunjukkan tentang adanya pelarangan menggunakan sunnah sebagai dalil dalam setiap urusan. Artinya bahwa agama tidak campur dalam urusan-urusan manusia yang dimotivasi oleh naluri dan kebutuhan kehidupan duniawinya. Seperti halnya masalah "peperangan" yang telah dijelaskan, bahwa untuk masalah teknis dan teknik peperangan itu diserahkan kepada umat manusia dengan cara mengkondisikan dengan ilmu pengetahuan dan teknologi yang dimiliki oleh umat manusia, serta peradaban umat manusia itu sendiri yang semakin maju dan berkembang. Hal ini berarti bahwa universalisme hadis Nabi saw mencakup untuk segala situasi dan kondisi (shalih li kulli zaman wa makan).

Sebagian dari mereka ada yang berusaha mengingkari adanya sistem politik dalam Islam secara total dengan berdasarkan hanya satu hadis ini saja. Dikarenakan menurut mereka, masalah politik, baik pokok maupun parsialnya, adalah urusan duniawi kita, maka otomatis kita lebih tahu tentangnya. Wahyu tidak mempunyai kompetensi untuk memberikan aturan dan petunjuk dalam masalah ini. Bagi mereka, Islam adalah agama tanpa Negara dan akidah tanpa syariat. Sebagian yang lain berusaha mengingkari adanya system ekonomi dalam Islam, juga dengan berdasarkan pada satu hadis ini.

Sebelum membahas lebih jauh tentang hadis tersebut guna menyanggah pendapat kedua kelompok ekstrem di atas, Al-Qardlawi mengutip pendapat para ahli Hadis yang mengomentari pendapat tersebut. Seperti pendapatnya muhaddis Syeikh Ahmad Syakir dalam Musnad Ahmad sebagai berikut: "la (Syekh Ahmad) berkata, "hadis ini telah didengung-dengungkan oleh orang-orang atheis mesir dan orang-orang yang terbaratkan, seperti para budak orientalis dan para murid missionaries, sebagai dalil untuk menyerang orang-orang bergelut dalam bidang syariat Islam. Mereka berusaha menghapus seluruh Sunnah dan mengingkari Syariat Islam dalam mengatur muamalah, tatanan social, dan sebagainya. Mereka berpendapat bahwa semua itu adalah urusan dunia dengan dasar hadis di atas.

${ }^{36}$ Abu Muhammad Ahmad bin Hanbal, Musnad Ahmad bin Hanbal dalam CD. Rom al-Hadis, Baqy al-Musnad alMukaśśirin hadis nomor ke-12086. 
2. Sunnah sebagai Pembimbing Akal dan Indra

Menurut Yusuf al Qardhawi bahwa dengan akan dan panca indra yang dimiliki manusia, mereka dapat memahami dirinya dan alam sekitarnya. Dengan akal dan panca indra, manusia dapat mengkaji dan mengerti hukum alam dan rahasia yang tersimpan di dalamnya. Yang membimbing akal adalah wahyu Ilahi dan wahyu itu diturunkan kepada Nabi saw. Wahyu tersebut berupa risalah penutup yang terdapat dalam aqluran, wahyu terakhir yang menjadi petunjuk umat manusia, dan berupa sunnah Nabi yang menjelaskan dan menguraikan kandungan Alquran. ${ }^{37}$

Dari seperti ini, ke-lihatan bahwa gagasan Yusuf al Qardhawi, adalah menempatkan Alquran dan sunnah sebagai sumber ajaran Islam yang utama, dan secara khusus, sunnah (hadis) merupakan instrument penting dalam mendorong akal dan indra untuk memahami fenomena alam. Sunnah juga menurutnya, merupakan sumber pengetahuan, baik yang berkenaan dengan religius (keagamaan), humaniora (kemanusiaan), dan sosial yang dibutuhkan umat manusia untuk meluruskan jalan mereka, membetulkan kesalahan mereka ataupun melengkapi pengetahuan eksprimental mereka. ${ }^{38}$ Sunnah dalam hal ini, sangat menyambut kehadiran akal dan indera manusia yang melahirkan ilmu pengathuan. Melalui arahan-arahan sunnah, justeru telah menciptakan iklim psikologis dan intelektual yang kondusif untuk terwujudnya kebangkitan ilmiah dalam dunia Islam.

3. Sunnah dan Urgensinya dalam Memahami Peradaban

Dalam khasanah intelektual sunnah sangat dengan peradaban, secara luas, dapat dijumpai beberapa petunjuk Nabi saw dalam sunnah yang mengarah pada persoalan fikih peradaban, perilaku beradab, dan bangunan peradaban. Fikih peradaban (al-figh al-hadhari) menurut Yusuf al Qardhawi adalah fikih yang menghantarkan manusia dari pemahaman yang dangkal (primitif) menuju pemahaman yang luas dan mendalam mengenai alam dan kehidupan. Dengan rumusannya seperti ini, maka rambu pertama bagi fikih peradaban adalah ayat dan hukum alam. ${ }^{39}$

Tanda-tanda kekuasaan Allah yang tersebar di seluruh alam ini, tidaklah dapat dimanfaatkan dan dibaca kecuali oleh orang-orang yang berakal dan fikih (pemahaman yang arif). Allah telah menciptakan langit dan bumi, silih bergantinya

\footnotetext{
${ }^{37}$ Lihat, al Qardhawi, Kayfa Nata'amal Ma'a as-Sunnah an-Nabawiyah.

38 Ibid.

${ }^{39}$ Yusuf al Qardhawi, Pengantar Kajian Islam (Jakarta: Pustaka al-Kautsar, 2000), 380. 
siang dan malam, ${ }^{40}$ Allah juga menjadikan bintang-bintang, dan menciptakan manusia dari seorang diri. ${ }^{41}$ Untuk memahami fenomenan alam yang digambarkan ini, maka manusia dengan fikihnya adalah bersifat abadi, tetapi tetap dan selalu dapat diperbaharui, karena dari waktu ke waktu Allah selalu menguakkan rahasia alam kepada makhluknya. Yang perlu dipahami, adalah bahwa alam ini tidak berjalan tanpa aturan melainkan semuanya mengikuti takdir (ketentuan) Allah. Inilah yang disebut hukum alam (sunnatullah).

Namun demikian, menurut pengakuan Yusuf al Qardhawi bahwa di antara sunnatullah tersebut, berimbas kepada merajalelanya degradasi moral, tersebarnya kemaksiatan dan kemungkaran, serta rusaknya kondisi umat dapat mendekatkan waktu kehancuran umat. Sungguh merupakan rahmat Allah yang tidak terhingga bahwa Dia tidak menghukum semua perbuatan manusia di dunia. Untuk menghindarkan kehancuran umat manusia dan agar kasih sayang atau rahmat Allah senantisa diberikanNya kepada umat manusia maka diperlukan perilaku yang beradab sebagaimana yang banyak dilansir dalam sunnah. Hal seperti secara tegas Alquran menyatakan bahwa Nabi saw adalah uswatun hasanah, atau dengan kata lain bahwa Nabi saw adalah yang paling beradab. Di sinilah pentingnya mengikuti sunnah dalam upaya meningkatkan peradaban manusia.

\section{F. Kesimpulan}

Berdasarkan permasalahan yang menjadi kajian yang dijelaskan oleh Yusuf al Qardhawi, memperlihatkan kepada kita bahwa ia merupakan sosok yang piawai dalam membahas sunnah sebagai sumber ilmu pengetahuan dan peradaban. la juga terkenal karena banyak memberikan sumbangan pemikiran, terbukti dengan banyaknya karyakarya/tulisan yang telah ia buat dan menjadi rujukan banyak orang. Salah satu karyanya yaitu sunnah sebagai sumber ilmu pengetahuan dan peradaban. la menanamkan kepada pembaca bahwa rasio (akal) mempengaruhi pola pikir setiap orang. Sehingganya, ia menekankan untuk menggunakan akal sesuai dengan keberfungsian yang Allah berikan. Contohnya saja ketika membahas mengenai alat indra manusia, ia menyebutkan bahwa manusia memiliki kelemahan dan kekurangan perihal alat indra yang ia miliki, serta bagaimana dalam mempergunakannya. Selanjutnya, Yusuf Qardhawi menjelaskan bahwa sunnah adalah tuntunan hidup manusia. Dengan memahami dan mempelajarinya, akan membawa manusia kepada

40 QS. Ali-Imran: 190.

${ }^{41}$ QS. al-An'am: 97. 
jalan yang benar, karena sunnah berada pada tingkatan yang tinggi setelah Al-Qur'an. Berkaitan dengan sunnah sebagai sumber peradaban, terlihat bahwa kajian yang dibahas merupakan sebuah upaya dalam membawa manusia menjadi pribadi yang memiliki ilmu pengetahuan pada peradaban zaman yang selalu mengalami kemajuan. Di sini, penulis berkesimpulan bahwa kajian yang dijelaskan oleh Yusuf al Qardhawi mengantarkan kita semua untuk memahami bahwa sunnah juga memberikan keterkaitan yang kuat pada peradaban kehidupan manusia. Dengan demikian, zaman yang mengalami kemajuan akan peradaban yang beranekaragam akan sesuai dengan sunnah dan Al-Qur'an bila umat selalu mengikuti ajaran Al-Qur'an dan ajaran Rasul dengan sebaik mungkin.

\section{G. Referensi}

Abidin, Zainal. Alam Kubur Dan Seluk-Beluknya. Jakarta: PT Rineka Cipta, 1993.

Al-Khatib, M. Ajjaj. Al-Sunnah Qabl al-Tadwin. Dar al-Fikr, 1981.

Al-Madjzub, Muhammad. 'Ulama Wa Mufakkirun 'Araftuhum. Beirut: Dar al-Nafais, 1977.

Al Qardhawi, Yusuf. As-Sunnah Sebagai Sumber Iptek Dan Peradaban. Jakarta: Pustaka Al-Kautsar, 1999. . Bagaimana Memahami Hadis Nabi SAW. Bandung: Karisma, 1993. . Fatawa Qardhawi. Terj. H. Abdurrahman Ali Bauzir. Surabaya: Risalah Gusti, 1996.

. Halal Dan Haram Dalam Islam. Terj. H. Muammal Hamidy. Surabaya: PT Bina Ilmu, 1976. .al-Ijtihad al-Mu'asir. Kairo: Dar al-Tauzi' wa an-Nashr al Islamiyah,t.t. . Hasan Al-Nadwi Dalam Kenangan Yusuf al Qardhawi. Jakarta: Kafila Press, 2000.

. Kayfa Nata'amal Ma'as Sunnah an Nabawiyah. Beirut: Darul Wafa, 1993.

. Pasang Surut Gerakan Islam. Terj. Faruq Uqbah. Jakarta: Media Dakwah, 1987.

. Pengantar Kajian Islam. Jakarta: Pustaka al-Kautsar, 2000.

An-Nabulsi, Ratib. 7 Pilar Kehidupan. Jakarta: Gema Insani Press, 2010.

As-Suyuthy, Jalaludin. Argumentasi As-Sunnah. Surabaya: Risalah Gusti, 1996.

Azami, M. M. Studies in Hadith Methodology and Literature. Indianapolis: American Trust Publication, 1997. 
Departemen Agama RI. Al-Qur'an Dan Terjemahnya, Revisi Terjemah Oleh Lajnah Pentashih Mushaf Al-Qur'an Departemen Agama RI. Surabaya: CV Fajar Mulya, 2009.

Fahimah, Siti “Hermeneutika Hadis: Tinjauan Pemikiran Yusuf Al-Qordhowi dalam Memahami Hadis". Refleksi, Vol. 16, No. 1, (April 2017).

Ghoffar, M. Abdul. Pemikiran Dr. Yusuf al-Qaradhawi Dalam Timbangan. Bogor: Pustaka Imam Asy-Syafi'i, 2003.

Hallaq, W.B. An introduction to Islamic Law. Cambridge: Cambridge University Press, 2009.

Ismail, M. Syuhudi. Kaidah Kesahahihan Sanad Hadis. 1st ed. Jakarta: Bulan Bintang, 1990.

Mosiba, Risna. 2017. "SUNNAH SEBAGAI SUMBER IPTEK DAN PERADABAN (Studi atas Pemikiran Yusuf Al Qardhawi)". Inspiratif Pendidikan, vol. 6, no. 2 (Juli, 2017).

Nasution, Harun. Kedudukan akal dalam Islam. Jakarta: Yayasan Idayu, 1982.

Rakhmat, Jalaluddin. Islam Alternatif. Bandung: Mizan, 1999.

Sa'id, Hammam bin Abdurrahim. al-Fikr al-Manhaji 'inda alMuhadditsin. Qatar : Ri'asat al-Mahakim al-Syar'iyyat wa al-Syuun al-Diniyyat, 1998.

Suryadilaga, M. Alfatih. Ulumul Hadis. Yogyakarta: Teras, 2010.

Syakir, Syeikh. Al-Ba'itsul-Hatsits. Beirut: Darul Kutub Ilmiyah, 1988.

Talimah, Ishom. Al Qardhawi Wa Fiqiha. Terj. Samson Rahman "Manhaj Fiqih Yusuf Qardhawi.” Jakarta: Pustaka Al-Kautsar, 2001. 